American Journal of Biochemistry and Biotechnology 4 (4): 408-415, 2008

ISSN 1553-3468

(C) 2008 Science Publications

\title{
Investigations in the molecular events of Transitional Cell Carcinoma of the Bladder
}

\author{
${ }^{1}$ H.S. Kadhim, ${ }^{1}$ A.S. Abdulamir and ${ }^{2}$ R.R. Hafidh, ${ }^{3}$ F. Abubaker and ${ }^{3}$ K.A. Abbas \\ ${ }^{1}$ Microbiology Research Department, \\ ${ }^{2}$ Institute of Bioscience, \\ ${ }^{3}$ Faculty of Food Science and Technology, University Putra Malaysia, 43400, Malaysia
}

\begin{abstract}
Problem Statement: Transitional Cell Carcinoma (TCC) of the bladder is a significant health problem worldwide. The molecular mechanisms of tumor development and progression are complicated but likely involve the interaction of tumor suppressor genes, oncogenes, cell cycle regulatory proteins and other factors. Hence this study tries to explore the role of p53, bcl-2, c-myc and $\mathrm{Ki}-67$ in TCC of the bladder in correlation with different clinicopathological criteria which are tumor grade, muscle invasion by the tumor and disease presentation, primary or recurrent tumor. Approach: Thirty patients with TCC of the bladder were involved in the period from March 2007 - May 2008. Tumors were diagnosed by histopathology and compared with 20 control subjects. The expressions of p53, bcl-2, c-myc and Ki-67 proteins were investigated by immunohistochemistry (IHC). Results: Increased expression of p53 and bcl-2 was associated with tumor grade and muscle invasion $(\mathrm{p}<0.05)$, but not with disease presentation $(\mathrm{p}>0.05)$. C-myc expression was only associated with muscle invasion $(\mathrm{p}<0.05)$. Ki-67 was associated with tumor grade, muscle invasion and tumor presentation $(\mathrm{p}<0.05)$. The correlation among these cell cycle proteins was generally significantly positive except for the correlation between bcl-2 and c-myc was poor. Conclusions: There was a significant oncogenic role of p53 and bcl-2 on TCC in terms of muscle invasion and tumor grade. C-myc was associated only with tumor invasiveness and Ki-67 proved to act as a reliable prognostic factor of TCC. This could highlight the hot targets of TCC anti-cancer therapy and the reliable targets for disease prognosis.
\end{abstract}

Key words: Immunohistochemistry, p53, bcl-2, Ki-67, c-myc, transitional cell carcinoma of the bladder

\section{INTRODUCTION}

Bladder cancer is the second most common malignancy of the genitourinary system $^{[1]}$. Acquired and inherited alterations of genes that function as regulators of cell growth and differentiation are considered as crucial steps in the initiation and progression of human malignancies ${ }^{[2]}$. The neoplastic change in the urothelium is a multistep phenomenon ${ }^{[3]}$. An initiator and its metabolites induce an alteration in normal cell DNA, which allows its transformation into a malignant cell through an alteration in the normal transfer of genetic information from DNA to RNA ${ }^{[3]}$. The exact genetic events leading to urothelial transformation are still unknown, but they are likely multiple and most probably involve the activation of oncogenes and the inactivation or loss of tumor suppressor genes ${ }^{[4]}$.

The c-myc gene has been shown to be overexpressed in several human tumors including bladder cancer. The genetic mechanism causing overexpression of the c-myc gene in bladder cancer is unknown. It could be related to hypomethylation ${ }^{[5]}$ and its overexpression has been shown to be associated with high-grade bladder cancer ${ }^{[6]}$.

P53 is known to play a vital role in the regulation of the cell cycle. Upon DNA damage, the level of p53 protein increases causing cell-cycle arrest. This allows for the repair of DNA and prevents propagation of the DNA defect ${ }^{[7]}$. The evidence that p53 dysfunction is relevant to human cancer is compelling. The contribution of defective p53 to human cancer development can be considered by following the individual cellular responses regulated by $\mathrm{p} 53$, as in loss of p53-dependent apoptosis, proliferative advantage, genomic instability and DNA repair and angiogenic control $\operatorname{loss}^{[8]}$. Mutations in the p53 gene result in the production of an abnormal and usually dysfunctional protein product with a prolonged half-life compared to the wild-type protein. Consequently, this

Corresponding Author: K.A. Abbas, Faculty of Food Science and Technology, University Putra Malaysia, 43400, UPM, Malaysia 
abnormal protein accumulates in the cell nucleus and can be detected by immunohistochemical staining ${ }^{[9]}$.

Overexpression of bcl-2 has been reported in a wide variety of cancers including prostate, colorectal, lung, renal, bladder and leukemia ${ }^{[10]}$. Several studies have provided conclusive evidence that elevations in bcl-2 expression cause resistance to chemotherapy and radiotherapy $^{[11]}$.

$\mathrm{Ki} 67$ was originally identified by its cell cycle related expression and it is now considered as one of the specific and important markers for cell proliferation $^{[9]}$. This nuclear antigen expressed during all phases of cell cycle, but not in the quiescent phase. Determination of the Ki-67 soon became widely used in surgical pathology. In most types of cancer (for example, carcinomas, sarcomas, lymphomas and gliomas), the Ki-67 was found to correlate with tumor grade and clinical course ${ }^{[12]}$.

This study aimed at investigating the interrelated role of a tumor suppressor protein, p53, an antiapoptotic protein, bcl-2, an oncogene, c-myc and a prolifertative marker, Ki-67 in patients with bladder TCC living in the region of The Middle East where no previous studies scrutinized the effect of these 4 markers together on TCC tumors. Moreover, this study granted a good chance to study the correlation behavior of these markers with each other in TCC patients.

\section{MATERIALS AND METHODS}

\section{The population of the study:}

Bladder cancer patients: Thirty patients ( 23 males and 7 females) with TCC of the bladder, who were confirmed histopathologically, were included in this study in the period from March 2007 - May 2008. The patients with bladder cancer and the control group subjects were retrieved, examined, interviewed and sampled in the region of The Middle East (Jordan, Syria and Iraq). The investigational study was conducted in University Putra Malaysia (UPM) in Malaysia. These patients' age ranged from 38-72 years. Patients were diagnosed clinically by consultant urologists. Eighteen patients presented with bladder tumor for the first time and 12 presented with recurrent bladder tumor that most of them were treated surgically. TCC patients staging was done according to TNM system and categorized accordingly into invasive (T2, T3 and T4) and non invasive tumors (Ta, T1 and CIS). Moreover, TCC cases were histologically graded as low grade (formerly graded 1-2) or high grade (formerly graded 3$)^{[1]}$. Information on the involved patients was obtained by a questionnaire including name, age, sex, address, time of the disease presentation and relevant medical history.
Written consents were granted by the involved patients for sampling of the study. The handling with human subjects was done under the permission of the regional committee of Ethics for biomedical research.

Control group: Twenty age- and sex- matched individuals, who were seeking urologists for lower urogential problems, were considered as control group whose bladder biopsies were investigated and were proved to be free of bladder cancer or any other bladder disease or inflammation. Consents were granted from the control group subjects to study their transurethral biopsies.

Specimens of tumor biopsy: The bladder cancer patients underwent either transurethral resection of bladder tumor (TUR-BT) or cystectomy biopsy. The specimens taken were multiple pieces, $1-5 \mathrm{~mm}$ in thickness and were immersed in $10 \%$ formalin in order to make a paraffin block.

Immunohistochemistry for p53, bcl-2, c-myc and Ki 67: Immunohistochemistry staining was done using a set of monoclonal primary antibodies; anti-p53 protein, anti bcl-2 protein, anti-c-myc protein (InnoGenex, USA), anti Ki-67 protein (DakoCytomation). The used procedure of IHC was according to the manufacturer instructions (LSAB2 Universal Dakocytomation strepavidin-biotin detection system). The working dilutions of antibodies used were 1:100, 1:75, 1:100 and 1: 50 for anti- p53, bcl-2, c-myc and $\mathrm{Ki}-67$ resepctively.

After baking slides in oven at $65^{\circ} \mathrm{C}$ overnight, slides were deparaffinized by applying sequential immersion for $5 \mathrm{~min}$ in xylene, 95\% ethanol, $70 \%$ ethanol and in DW respectively. In order to obtain the best results, autoclave-based antigen retrieval was done. Slides were placed in a jar containing antigen retrieval solution $(0.1 \mathrm{M}$ citrate buffer, $\mathrm{pH} 6)$ and left in the autoclave, for $2-4 \mathrm{~min}$ under $121^{\circ} \mathrm{C}$. Then, $100 \mu \mathrm{L}$ of the diluted primary antibody was applied onto the sections and the slides were placed in the humid chamber incubated at $4^{\circ} \mathrm{C}$ overnight. The next day, slides were rinsed gently with PBS-Tween and placed in fresh PBS-Tween bath for $1 \mathrm{~min}$. One-two drops of the biotinylated secondary goat anti-mouse antibodies (DakoCytomation) were applied onto the sections and slides were placed in the humid chamber and incubated at $37^{\circ} \mathrm{C}$ for $1 \mathrm{~h}$. After rinsing step, One-two drops of streptaviden-Horseradish peroxidase (HRP) reagent (dakocytomation) was applied onto the sections, slides were placed in humid chamber and incubated at $37^{\circ} \mathrm{C}$ for $30 \mathrm{~min}$. The prepared DAB-substrate chromogen solution was applied onto sections, slides were 
incubated in dark at room temperature for $20 \mathrm{~min}$. Mayer's hematoxylin stain was used as counterstain, then slides were dehydrated and mounted with DPX mounting fluid.

Staining analysis: Slides were examined by pathologist by light microscope at X40 magnification (Fig. 1). Immunostaining was scored according to certain cut-off values calculated in other reports. The cut-off for positivity was $>5 \%$ positive nuclei for $\mathrm{p} 53^{[13]}, 10 \%$ positive cells for bcl- $2^{[14]}, 10 \%$ positive cells for $\mathrm{Ki}-$ $67^{[15]}$ and $5 \%$ positive cells for c-myc immunostaining ${ }^{[16]}$. Semi-quantitative IHC scoring was done (Table 1).

Statistical analysis: It was conducted using SPSS software version 10 and MS Excel 2000. Chisquare test of independence was used for evaluating the

Table 1: The semi-quantitative scoring of $\mathrm{p} 53$ and bcl-2

\begin{tabular}{lllll}
\hline Marker & Negative & Low & Moderate & High \\
\hline p53 & $<5 \%$ & $5-25 \%$ & $25-50 \%$ & $>50 \%$ \\
bcl-2 & $<10 \%$ & $10-50 \%$ & --- & $>50 \%$ \\
\hline
\end{tabular}

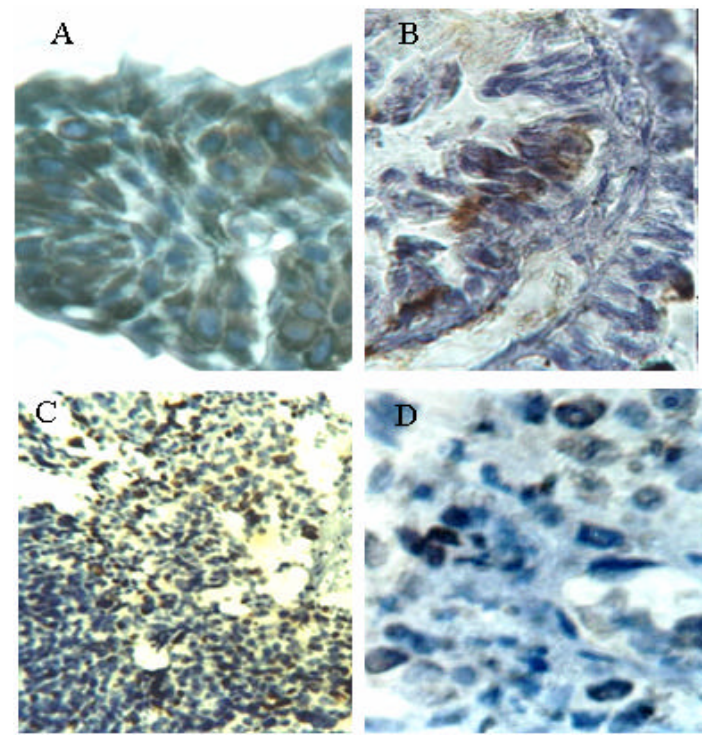

Fig. 1: Immunohistochemical staining in TCC of bladder tumor sections. Immunostaining by peroxidase/DAB (brown) counterstained with hematoxylin. (A): Bladder tumor (TCC), c-myc protein cytoplasmic staining in high-grade tumor (X40). (B): TCC, p53 nuclear stains in low-grade tumor (X100). (C): TCC, bcl-2 nuclear staining high-grade tumor (X20). (D): TCC, Ki-67 nuclear staining in advanced tumor $(\mathrm{X} 40)$ significant association of the positive studied markers in relation to several clinopathological criteria, namely tumor presentation, muscle invasion and tumor grade. After proving that all studied samples obey the normal distribution pattern using Kolmogorov and Smirnov normalization tests, parametric tests of significant difference were used namely Pearson's correlation coefficient ( $r$ ) to study the correlation between different IHC markers. p-values less than 0.05 were considered as significant.

\section{RESULTS}

The histopathological examination revealed that 20 bladder cancer patients were with high grade tumors versus 10 of low grade tumors. And 17 of them were with invasive tumors versus 13 with non-invasive tumors. The IHC findings of he retrieved tissue sections showed that all of the studied markers namely, p53, bct 2, c-myc and Ki-67 proteins were expressed positively remarkably higher than that in control subjects $(p<0.05)$. This indicated the essential role that these markers appear to play in the pathogenesis of TCC of bladder (Table 2).

It was found that the score 'High' of p53 expression was the most frequent among the p53positive patients, $43.75 \%$. It was shown that the p53 positive expression was not associated significantly with disease presentation $(p>0.05)$. On the other hand, it was associated with high grade histopathology and highly muscle-invasive tumors $(\mathrm{p}<0.05)$ (Table 3, Fig. 2).

Table 2: A comparative table between the number and percentage of bladder cancer patients and control subjects showed positive IHC expression of p53, bcl-2, c-myc, and Ki-67

\begin{tabular}{llll}
\hline $\begin{array}{l}\text { The } \\
\text { histopathological } \\
\text { marker }\end{array}$ & $\begin{array}{l}\text { The No. (\%) } \\
\text { of patients } \\
\text { with positive } \\
\text { expression }\end{array}$ & $\begin{array}{l}\text { The No. (\%) of } \\
\text { control subjects } \\
\text { with positive } \\
\text { expression }\end{array}$ & p-value \\
\hline P53 & $16 / 30(53.3)$ & $0 / 20(0)$ & $<0.0001$ \\
Bcl-2 & $15(50 \%)$ & $1 / 20(5)$ & $<0.0001$ \\
c-myc & $17 / 30(56.66)$ & $0 / 20(0)$ & $<0.0001$ \\
Ki-67 & $24 / 30(80)$ & $3 / 20(15)$ & $<0.0001$ \\
\hline
\end{tabular}

Table 3: The percentage of $\mathrm{p} 53$ overexpression in relation to the clinicopathological criteria

\begin{tabular}{lcc}
\hline Criteria (number) & $\begin{array}{l}\text { The No. (\%) of the } \\
\text { positive p53 patients }\end{array}$ & p-value \\
\hline $\begin{array}{l}\text { How grade tumor (10) } \\
\text { High grade tumor (20) }\end{array}$ & $2(20.0)$ & 0.02 \\
$\begin{array}{l}\text { Tumor invasion } \\
\text { Invasive tumor (17) }\end{array}$ & $12(70.0)$ & \\
$\begin{array}{l}\text { Non-invasive tumor (13) } \\
\text { Presentation }\end{array}$ & $4(30.7)$ & 0.03 \\
$\begin{array}{l}\text { Recurrent tumor (12) } \\
\text { Primary tumor (18) }\end{array}$ & $7(58.3)$ & \\
\hline
\end{tabular}


Am. J. Biochem. \& Biotech., 4 (4): 408-415,2008

Table 4: The percentage of bcl-2 expression in relation to the clinicopathological criteria

\begin{tabular}{lcc}
\hline Criteria (number) & $\begin{array}{l}\text { The num ber (\%) of the } \\
\text { positive bcl-2 patients }\end{array}$ & p-value \\
\hline $\begin{array}{l}\text { Histopathology } \\
\text { Low grade tumor (10) }\end{array}$ & $2(20.00)$ & 0.02 \\
$\begin{array}{l}\text { High grade tumor (20) } \\
\text { Tumor invasion }\end{array}$ & $13(65.00)$ & \\
$\begin{array}{l}\text { Invasive tumor (17) } \\
\text { Non-invasive tumor (13) }\end{array}$ & $\begin{array}{r}12(70.50) \\
\text { Presentation }\end{array}$ & 0.01 \\
$\begin{array}{l}\text { Recurrent tumor (12) } \\
\text { Primary tumor (18) }\end{array}$ & $5(41.66)$ & \\
\hline
\end{tabular}

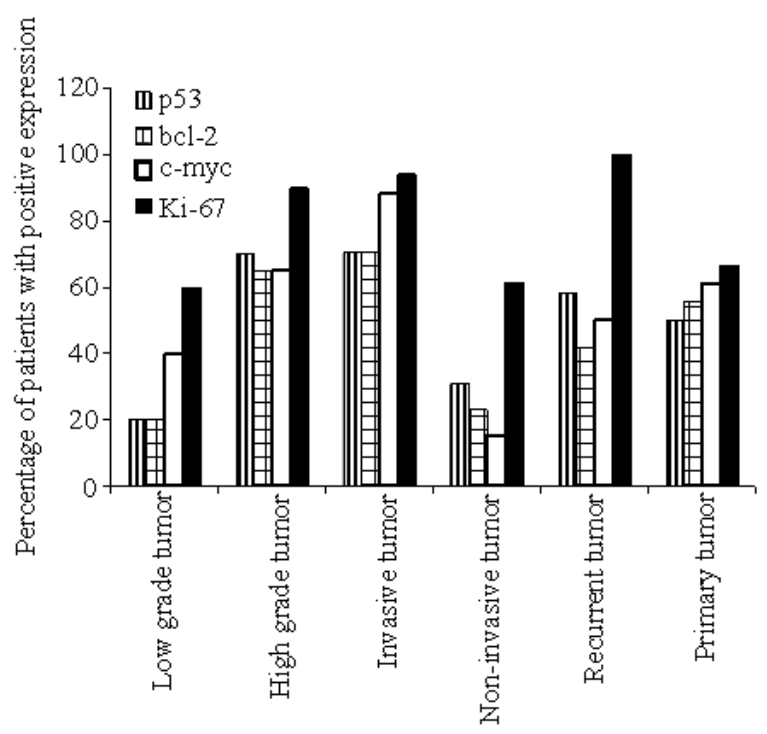

Fig. 2: The percentage of bladder cancer patients with positive expression of $\mathrm{p} 53$, bcl-2, c-myc and $\mathrm{Ki}$ 67 proteins in IHC tissue sections in relation to the studied clinicopathological criteria

The bcl-2 expression at the score 'High' was $32.37 \%$. It was shown that the bcl-2 positive expression is associated significantly with histopathology favoring high tumor grade and muscle invasion favoring invasive tumors $(\mathrm{P}<0.05)$. On the other hand, It was not associated with the disease presentation $(\mathrm{P}>0.05)$ (Table 4, Fig. 2).

Regarding c-myc protein, it was shown that the cmyc positive expression was significantly associated with muscle invasion favoring invasive tumors $(\mathrm{p}<0.05)$ whereas it was not associated with tumor grade or disease presentation ( $\mathrm{p}>0.05$ ) (Table 5, Fig. 2).

$\mathrm{Ki}-67$ protein positive staining was extensively prominent in bladder tumors, $24(80 \%)$. It was shown that the Ki-67 positive expression was associated significantly with histopathology favoring high tumor grade, tumor invasion favoring invasive tumors and with the disease presentation favoring recurrent tumors $(\mathrm{p}<0.05)$ (Table 6, Fig. 2).
Table 5: The expression of c-myc protein in relation to the clinicopathological criteria

\begin{tabular}{lcc}
\hline $\begin{array}{l}\text { Criteria (number) } \\
\text { positive c-myc patients }\end{array}$ & p-value \\
\hline $\begin{array}{l}\text { Histopathology } \\
\text { High grade tumor (10) }\end{array}$ & $4(40.00)$ & 0.193 \\
$\begin{array}{l}\text { Tumor invasion } \\
\text { Invasive tumor (17) }\end{array}$ & $13(65.00)$ & \\
$\begin{array}{l}\text { Non-invasive tumor (13) } \\
\text { Presentation }\end{array}$ & $15(88.23)$ & 0.006 \\
$\begin{array}{l}\text { Recurrent tumor (12) } \\
\text { Primary tumor (18) }\end{array}$ & $6(15.38)$ & \\
\hline
\end{tabular}

Table 6: The results of $\mathrm{Ki}-67$ staining in relation to the clinicopathological criteria

\begin{tabular}{lcc}
\hline Criteria (number) & $\begin{array}{l}\text { The No. (\%) of the } \\
\text { positive Ki-67 patients }\end{array}$ & p-value \\
\hline $\begin{array}{l}\text { Histopathology } \\
\text { Low grade tumor (10) }\end{array}$ & $6(60.0)$ & 0.048 \\
$\begin{array}{l}\text { High grade tumor (20) } \\
\text { Tumor invasion }\end{array}$ & $18(90.0)$ & \\
$\begin{array}{l}\text { Invasive tumor (17) } \\
\text { Non-invasive tumor (13) }\end{array}$ & $\begin{aligned} 16(94.1) \\
8(61.5)\end{aligned}$ \\
$\begin{array}{l}\text { Presentation } \\
\text { Recurrent tumor (12) }\end{array}$ & $12(100)$ & 0.027 \\
Primary tumor (18) & $12(66.6)$ & 0.025 \\
\hline
\end{tabular}

Table 7: Pearson's correlation coefficient (r) among the IHC expression of p53, bcl-2, cmyc and ki-67 in the studied bladder cancer patients

\begin{tabular}{lll}
\hline Marker 1 vs. marker 2 & Correlation coefficient (r) & $\mathrm{p}$-value \\
\hline P53 vs. bcl-2 & 0.733000 & $\mathrm{p}<0.05$ \\
P53 vs. c-myc & 0.665184 & $\mathrm{p}<0.05$ \\
P53 vs. Ki-67 & 0.534522 & $\mathrm{p}<0.05$ \\
Bcl-2 vs. c-myc & 0.067267 & $\mathrm{p}>0.05$ \\
Bcl-2 vs. Ki-67 & 0.500000 & $\mathrm{p}<0.05$ \\
c-myc vs. Ki-67 & 0.571772 & $\mathrm{p}<0.05$ \\
\hline
\end{tabular}

The correlations among the studied markers: Correlations among the IHC expression of the studied markers namely, p53, bcl-2, c-myc and ki-67 were made using Pearson's correlation coefficient (r). It was found that p53 and Ki-67 expression was correlated positively with all other markers and with each other $(\mathrm{p}<0.05)$. Cmyc and bcl-2 expression was correlated positively with other markers $(p<0.05)$ except the correlation of c-myc with bcl-2 was not significant ( $>0.05)$ (Table 7). This indicated that p53, bcl-2, Ki67 and c-myc proteins in TCC tissues increase or decrease largely in parallel which points out to the presence of a well integrated network of oncogenes, tumor suppressor proteins, cell cycle regulators and proliferation markers that might initiate and/or maintain the cancerous status of TCC of bladders.

\section{DISCUSSION}

The molecular phenotyping has provided new dimensions to the characterization of the biological potential of tumors that may help better predict their 
clinical outcome. Different studies have indicated that alteration in cell cycle regulation is a key event in determining the biological behavior of bladder cancer $^{[17]}$.

In this study, mutant-type p53 was detected by IHC, a technique is sensitive enough to consider its result. Mutated-p53 protein shows much longer half-life than wild type, allowing its detection by IHC. It acts by forming complexes with the wild type, prohibiting its function. P53 positive expression was differentially found in $70 \%$ of high-grade and $75 \%$ in invasive tumors, while in low grade, its expression was scanty, $20 \%(\mathrm{p}<0.05)$. In this study, results have showed that p53 protein was associated with the tumor grade and the disease progression to invasive tumor. These results are in agreement with Atug et al. ${ }^{[18]}$ who showed a similar association with tumor grade as p53 was detected in $75 \%$ of high grade tumor and $25 \%$ of low grade tumor. Unfortunately, they did not focus on the role of muscle invasion. Nakopoulou et al. ${ }^{[19]}$ showed that p53 overexpression was detected in $50 \%$ of TCCs especially in muscle -invasive carcinomas.

The effect of the mutated p53 is to inhibit the wild type function, namely cell cycle arrest and apoptosis, driving tumors to proliferate and increase in size. This increment in the tumor stroma will affect the microenvironment circulation in the surrounding normal tissue, reducing the infiltration of immune cells to the area with reduction in the cytokines level. Hence, a state of local immunosuppression will take place ${ }^{[20]}$. Moreover, the increase in the size of tumors requires new blood vessel formation. Therefore, angiogenesis is needed and formation of new blood vessels is enhanced. The process of angiogenesis helps increase the tumor size and facilitates metastasis ${ }^{[21]}$. Dysfunction of p53 also gives hand to angiogenesis and hence metastasis ${ }^{[21]}$. Therefore in bladder cancers, the overexpression of p53 represents the accumulation of mutated dysfunctional version of the protein leading to a state of high rate proliferation, immunosuppression, where all increase the invasiveness and aggressiveness of the tumor as what is found in this study.

The current study revealed that $50 \%$ of patients showed positive expression of bcl-2. And $65 \%$ of the high-grade tumors and $20 \%$ of low-grade tumors showed positive bcl-2 expression. Hence, Bcl-2 was shown to be significantly associated with tumor grade ( $\mathrm{p}<0.05$ ). Furthermore, $70.5 \%$ of the invasive tumors showed positive bcl-2 expression versus only $23 \%$ in non-invasive tumors $(\mathrm{p}<0.05)$. These findings are in agreement with the study of Atug et al. ${ }^{[18]}$ who stated that the positive immunostaining of bcl-2 was observed in $69 \%$ of bladder cancers where $75 \%$ of patients were with high-grade tumors and only $25 \%$ with low-grade tumors which confirmed the significant bcl-2 association with the tumor grade. However, our results showed some differences with that of Nakopoulou et al. ${ }^{[19]}$ who stated that bcl-2 was observed in $52 \%$ of bladder cancer patients where $57 \%$ of them were of low-grade and $43 \%$ of high-grade tumors. In addition, the results of Shiina et al. ${ }^{[22]}$ was different too form our results. They showed that the expression of bcl-2 was observed only in $24.7 \%$ of bladder cancer cases and stated that this expression inversely correlated with tumor grade and was not correlated with tumor stage.

One potential explanation for the high levels of bcl-2 expression in bladder cancer patients is the loss of p53 function. The loss of p53 may enhance the expression of bcl-2, by relieving it from the transcriptional repression of the wild type p53 protein $^{[11]}$. This was confirmed by the highly significant direct correlation found between the IHC expression of bcl-2 and that of p53 $(\mathrm{P}<0.05)$. Given the main reason of the high p53 positive expression in bladder cancers is the formation of dysfunctional mutated p53, therefore the higher the p53 in bladder cancer the higher the mutated p53 leading to less functional wild p53. Accordingly, less wild p53 leads to higher bcl-2 and decreased apoptosis. Bcl-2 prevents the interaction between Bax and Bak, which in turn prevents the release of the cytochrome $c$ from mitochondria, resulting in the prevention of apoptosis ${ }^{[10]}$. Moreover, bcl-2 sequesters caspase activators and this prevents caspase activation which subsequently prevents apoptosis and the tumor cell then proliferate ${ }^{[10]}$. It is known that the dysfunction of p53 alone does not always cause neoplastic transformation. So, overexpression of bcl-2 could worsen the condition leading to the condition where the tumor will increase in stroma affecting the microcirculation ${ }^{[23]}$. It is noteworthy to mention one of the interesting observations in this study which implied on the effect of bcl-2 in the chemotherapy resistance of bladder cancers. Most of bladder tumors involved in this study with high bcl-2 expression have shown remarkable resistance to the most known cytotoxic drugs and this may require further prospective study with follow up to demonstrate this particular role.

In this study, $56.7 \%$ of patients showed positive immunostaining for $\mathrm{c}$-myc protein. The positive expression of c-myc was not associated with tumor grade ( $p>0.05) .40 \%$ of low-grade tumor patients were with positive c-my expression and $53 \%$ were with high grade tumors. However, muscle invasion was significantly associated $(\mathrm{p}<0.05)$ with $\mathrm{c}-\mathrm{myc}$ expression 
as $88.23 \%$ of invasive tumor patients showed positive c-myc expression. This finding is in agreement with Schmitz-Drager et al. ${ }^{[24]}$ who showed that $58 \%$ of their patients were cmyc positive. They also revealed that $59 \%$ of the positive cases were of muscle-invasive tumors. They concluded that c-myc over-expression did not correlate with tumor grade or tumor progression $^{[26 ; 24]}$. In present study, c-myc overexpression was not significantly $(p>0.05)$ associated with disease presentation whether recurrent or primary tumor. Lipponen ${ }^{[25]}$ showed that $34 \%$ of patients had positive c-myc and they found that c-myc expression was associated with tumor grade but with no prognostic value. Nevertheless, c-myc proved in this study that it is actively engaged in the pathogenesis of bladder cancer due to many reasons; positive c-myc expression was found in $57 \%$ of patients, its association with tumor muscle invasion and it was significantly correlated positively with both p53 and Ki-67 proteins. Consequently, c-myc seems one of the oncogens implicated in TCC of bladder cancers. Gmyc might play its pathogenic role in bladder tumors through inducing proliferation rather than apoptosis ${ }^{[26]}$. The induction of apoptosis is known to be through p53 gene. Wild type p53 represses c-myc expression most likely through transcription. Consequently, when c-myc is overexpressed due to p53 dysfunction, this promotes aggressive cell growth and transformation ${ }^{[26]}$. Therefore, it is not surprising that p53 mutation and deregulated c-myc expression are common events in human cancers. The defect in c-myc could start in early stages of the disease and this defect is irreversible which is indicated by the non-added effects in late stage, but rather, it may open windows for other defects to take place, increasing the severity of the disease ${ }^{[27]}$. Hence, one can assume that, c-myc might be necessary but not sufficient for the induction of proliferation in bladder cancer and further studies are needed to pinpoint its role bladder oncogenesis.

The proliferation index of $\mathrm{Ki}-67$ is an important marker to assess whether the cell is in the proliferative phase or not. It is expressed throughout all phases of the cell cycle except in the quiescent phase $\left(\mathrm{G}_{0}\right)$. In cancer cells, Ki-67 plays an important role as an index for the replication and the prognosis ${ }^{[328]}$. In addition, it is well associated to tumor grade, stage and recurrence ${ }^{[28]}$. In this study, Ki-67 was positively expressed in $80 \%$ of bladder cancer patients. And it was significantly $(\mathrm{p}<0.05)$ associated with tumor grade in that $90 \%$ of high-grade tumors showed positive Ki-67 expression versus $60 \%$ in low-grade tumors. Moreover, it was significantly $(\mathrm{p}<0.05)$ associated with invasive tumors, $94.1 \%$ and with recurrent tumors, $100 \%$. This is in agreement with $^{[19,15,29]}$ who showed that Ki-67 positive immunostaining was correlated with tumor grade and muscle invasion. It is noteworthy to mention that Ki-67 expression was significantly correlated positively with all other studied markers namely p53, bcl-2 and c-myc. This provided evidence that $\mathrm{Ki}-67$ is central in the parthenogenesis of bladder cancer and it reflects the status of increased proliferation potential of the cancerous cells. Accordingly, Ki-67 positive immunostaining in bladder tumor reflects the proliferation process in this tumor. Its detection reflects that this antigen is present in most cell cycle steps, but not in resting cells.

\section{CONCLUSION}

Taken together, p53 has the upper hand in the bladder oncogenesis. This study showed that p53 was overexpressed in bladder cancer which was most probably a mutated type. P53 was associated with tumor progression, reflected by the association with tumor grade and muscle invasion. P53 mutation affects other cell cycle proteins, like bcl-2, which aggravates the disease condition. Bcl-2 also was shown to be associated with tumor growth and progression via its association with high tumor invasiveness and high tumor grade which all aggravate the bladder cancer. The oncogene c-myc could play its role through a self mutation or due to p53 mutation. Unlike p53 and bcl-2, $\mathrm{C}$-myc proved to aggravate the invasiveness of tumors rather than tumor grade or progression. Ki-67 reflected successfully the increased proliferation of tumor cells which was affected by the other studied markers. Ki-67 was the only marker that associated with tumor presentation which renders it as a good prognostic marker.

\section{REFERENCES}

1. Daniel, L., 2008. TNM staging: The commonc language for cancer care. Am. Joint Committee Cancer, 28 Jul. 2008; http://www.cancerstaging.org/mission/whatis.html

2. Shirai, T., 1993. Etiology of bladder cancer. Semin.Urol., $\quad 3: \quad 113-116$. http://www.ncbi.nlm.nih.gov/pubmed/8210833?do $\mathrm{pt}=$ Citation

3. Carroll, P.R., 1995. Urothelial Carcinoma: Cancers of the Bladder Ureter and Renal Pelvis. In: General Urology, Tanagho, E.A. and J.W. McAninch (Eds.). Prentice-Hall International Inc., USA., pp: 353-372.

4. Sandberg, A.A. and C.S. Berger, 1994. Review of chromosome studies in urological tumors. II. Cytogenetics and molecular genetics of bladder cancer. J. Urol., 151: 545-560. http://www.ncbi.nlm.nih.gov/pubmed/7905930?do $\mathrm{pt}=$ Citation 
5. Del Senno, L., I. Maestri, R. Piva, S. Hanau, A. Reggiani, A. Romano and G. Russo, 1989. Differential hypomethylation of the c-myc protooncogene in bladder cancers at different stages and grades. J. Urol., 142: 146-149. http://www.ncbi.nlm.nih.gov/entrez/query.fcgi?cm $\mathrm{d}=$ Retrieve $\& \mathrm{db}=$ PubMed $\& \mathrm{dopt}=$ Citation\&list_uids $=2733094$

6. Williams, S.G., M. Buscarini and J.P. Stein, 2001. Molecular markers for diagnosis, staging and prognosis of bladder cancer. Oncology, 15:

http://www.cancernetwork.com/bladdercancer/article/10165/99748

7. Zamamiri, F.A. and G.P. Zambetti, 2004. p53 Tumor Suppressor Genes. In: Cell Cycle and Growth Control, Biomolecular Regulation and Cancer, Stein, G.S. and A.B. Pardee (Eds.). John Wiley and Sons, Inc., Hoboken, New Jersey.pp: 365-371.

8. Bellamy, C.O., R. Malcomson and A. Wyllie, 1997. The Role of p53 in Apoptosis and Cancer. In: Apoptosis and Cancer, Martin, S.J., (Ed.). Karger Landes Systems, Basel, Switzerland, pp: 114-140.

9. Hayat, M.A., 2002. Microscopy, Immunohistochemistry and Antigen Retrieval Methods for Light and Electron Microscopy. 1st Edn., Kluwer Academic/Plenum Publishers, New York, ISBN: 0306467704, pp: 360-366.

10. Cho, H.J., J.K. Kim, K.D. Kim, H.K. Yoon, M.Y. Cho, Y.P. Park, J.H. Jeon, E.S. Lee, S.S. Byun, H.M. Lim, E.Y. Song, J.S. Lim, D.Y. Yoon, H.G. Lee and Y.K. Choe, 2006. Upregulation of Bcl-2 is associated with cisplatinresistance via inhibition of Bax translocation in human bladder cancer cells. Cancer Lett., 237: 56-66. DOI: S0304-3835(05)00539-2

11. Reed, J.C., 1997. Bcl-2 Family Proteins: Role in Dysregulation of Apoptosis and Chemoresistance in Cancer. In: Apoptosis and Cancer, Martin, S.J. (Ed.). Karger Landes Systems, Basel, Switzerland. pp: 64-97.

12. Lindboe, C.F. and S.H. Torp, 2002. Comparison of Ki-67 equivalent antibodies. J. Clin. Pathol., 55: 467-471. http://www.pubmedcentral.nih.gov/articlerender.fc gi?tool=pubmed $\&$ pubmedid $=12037032$

13. Kraggerud, S.M., K.D. Jacobsen and A. Berner, 1997. A comparison of different modes of the detection of p53 protein accumulation, a study of bladder cancer. Pathol. Res. Pract., 193: 471-478. http://www.ncbi.nlm.nih.gov/pubmed/9342752 or http://journals.indexcopernicus.com/abstracted.php ?level $=5 \&$ icid $=611450$
14. Ong, F., L.M. Moonen and M.P. Gallee, 2001. Prognostic factors in TCC of the bladder: an emerging role for bcl-2 and p53. Radiother. Oncol., 61: 169-175. DOI: 10.1016/S0167-8140(01)004212

15. Pfister, C., L. Moore, P. Allard, H. Larue and Y. Fradet, 1999 . Predictive value of cell cycle markers p53, MDM 2, p21 and Ki-67 in superficial bladder tumor recurrence. Clin. Cancer Res., 5: 4079-4084. http://clincancerres.aacrjournals.org/cgi/content/ful 1/5/12/4079.

16. Pich, A., M. Margaria, L. Chiusa, P. Bortolin and G. Palestro, 2003. Relationship between AgNORs, MIB-1 and oncogene expression in male breast carcinoma and papillary superficial bladder neoplasm. Oncol. Rep., 10: 1329-1335. http://cat.inist.fr/?aModele $=$ afficheN\&cpsidt $=1494$ 1760

17. Cordon-Cardo, C., 1995. Mutation of cell cycle regulators: biological and clinical implications for human neoplasia. Am. J. Pathol., 147: 545-560. http://www.pubmedcentral.nih.gov/articlerender.fc gi?artid=1870966

18. Atug, F., L. Turkeri, M. Ozyurek and A. Akdas, 1998. bcl-2 and p53 overexpression as associated risk factors in TCC of the bladder. Int. Urol. Nephrol., 30: 455-461.DOI: 10.1007/BF02550226

19. Nakopoulou, L., C. Vourlakou and A. Zervas, 1998. The prevalence of bcl-2, p53 and $\mathrm{Ki}-67$ immunoreactivity in transitional cell bladder carcinomas and their clinicopathologic correlates. Hum. Pathol., 29: 146-154. http://cat.inist.fr/?aModele $=$ afficheN\&cpsidt $=2184$ 118

20. Mitra, A.P., M. Birkhahn and R.J. Cote, 2007. p53 and retinoblastoma pathways in bladder cancer. World J. Urol., 25: 563-571. DOI: 10.1007/s00345007-0197-0

21. Black, P.C. and C.P. Dinney, 2007. Bladder cancer angiogenesis and metastasis--translation from murine model to clinical trial. Cancer Metastas. Rev., 26: 623-634. DOI: 10.1007/s10555-0079084-9

22. Shiina, H., M. Igawa and S. Urakami, 1996. Immunohistochemical analysis of bcl-2 expression in TCC of the bladder. J. Clin. Pathol., 49: 395-399. DOI: $10.1136 /$ jcp.49.5.395

23. Maluf, F.C., C. Cordon-Cardo, D.A. Verbel, J.M. Satagopan, M.G. Boyle, H. Herr and D.F. Bajorin, 2006. Assessing interactions between mdm-2, p53 and bcl-2 as prognostic variables in muscle-invasive bladder cancer treated with neoadjuvant chemotherapy followed by locoregional surgical treatment. Ann. Oncol., 17: 1677-1686. DOI: 10.1093/annonc/mdl289 
24. Schmitz-Drager, B.J., W.A. Schulz, B. Jurgens, C.D. Gerharz, C.R. van Roeyen and H. Bultel, 1997. c-myc in bladder cancer, clinical findings and analysis of mechanism. Urol. Res., 25: S45-S49. DOI: 10.1007/BF00942047

25. Lipponen P.K. 1995. Expression of c-myc protein is related to cell proliferation and expression of growth factor receptors in transitional cell bladder cancer. J. Pathol., 175: 203-210. 10.1002/path.1711750208

26. Momota, H., A.H. Shih, M.A. Edgar and E.C. Holland, 2008. c-Myc and beta-catenin cooperate with loss of p53 to generate multiple members of the primitive neuroectodermal tumor family in mice. Oncogene, 27: 4392-4401. DOI: onc200881 [pii]

27. Papaggeli, P.C., A.C. Kortsaris and P.T. Matsouka, 2003. Aberrant methylation of c-myc and efos protooncogenes and p53 tumor suppressor gene in myelodysplastic syndromes and acute nonlymphocytic leukemia. J. Balkan Union Oncol., 8: 341-350. http://www.ncbi.nlm.nih.gov/ pubmed/17472275.
28. Masliukova, E.A., K.M. Pozharisskii, M.I. Karelin, V. Startsev and V.P. Ten, 2006. Role of Ki-67, mutated gene-suppressor p53 and HER-2neu oncoprotein in the prognosis for the clinical course of bladder cancer. Vopr. Onkol., 52: 643-648. http://www.ncbi.nlm.nih.gov/pubmed/17338241.

29. Tsuji, M., K. Kojima and Y. Murakami, 1997. Prognostic value of Ki-67 antigen and p53 protein in urinary bladder cancer: Immunohistochemical analysis of radical cystectomy specimens. Br. J. Urol., 79: 367-372. DOI: 10.1046/j.1464 410X.1997.02710.x 